\title{
Maternal perceptions and self-perception of the nutritional status of children and adolescents from private schools
}

\author{
Ney Boa-Sorte, 1 Luciana A. Neri, ${ }^{2}$ Maria Efigênia Q. Leite, ${ }^{3}$ Sheila M. Brito, ${ }^{2}$ \\ Ana Regina Meirelles, ${ }^{4}$ Fábia B. S Luduvice, 4 Jamille P. Santos, 4 \\ Marcela R. Viveiros, ${ }^{4}$ Hugo C. Ribeiro-Jr. ${ }^{5}$
}

\begin{abstract}
Objective: To describe and compare maternal perception and the self-perception of children/adolescents of their nutritional status, identifying factors associated with incorrect perceptions.

Methods: Cross-sectional study carried out in Salvador, BA, Brazil with 1,741 students aged 6 to 19 years, classified according to body mass index (BMI) percentiles as underweight (BMI $<$ p5), well-nourished ( $55 \leq$ BMI $<$ p85), at risk of overweight (p85 $\leq$ BMI $<$ p95) or overweight (BMI $\geq$ p95). Students and their mothers answered questions on perception of weight, patterns of physical exercise and dieting. By means of multivariate analysis, factors associated with incorrect maternal and self- perceptions were analyzed.

Results: Self-perceptions were correct in $64.7 \%$ of cases and $75.3 \%$ of maternal perceptions were correct. The principal factor associated with incorrect self-perception was age between 6 and 9 years $(\mathrm{OR}=1.59 ; 95 \% \mathrm{CI}$ 1.15-2.20). Among girls, being overweight and practicing physical exercise were characteristics associated with better perception. For boys, the presence of overweight resulted in an increased risk of incorrect self-perception. Among mothers, having an overweight child $(\mathrm{OR}=3.02 ; 95 \% \mathrm{CI} 2.05-4.46)$ and a child aged from 6 to 9 years $(\mathrm{OR}=$ $1.88 ; 95 \%$ CI 1.28-2.76) were associated with incorrect perception.

Conclusions: A failure to correctly perceive weight was very frequent among children and their mothers, especially when children were overweight. These factors could represent obstacles to correctly recognizing nutritional abnormalities.
\end{abstract}

J Pediatr (Rio J). 2007;83(4):349-356: Body image, overweight, childhood obesity, physical activity, adolescent.

1. Mestre. Médico, Centro de Pesquisas Fima Lifshitz, Departamento de Pediatria, Faculdade de Medicina da Bahia, Universidade Federal da Bahia (UFBA), Salvador, BA, Brasil.

2. Professora assistente, Curso de Nutrição, Faculdade de Tecnologia e Ciências, Salvador, BA, Brasil.

3. Nutricionista, Centro de Pesquisas Fima Lifshitz, Departamento de Pediatria, Faculdade de Medicina da Bahia, UFBA, Salvador, BA, Brasil.

4. Nutricionista, UFBA, Salvador, BA, Brasil.

5. Doutor. Chefe, Centro de Pesquisas Fima Lifshitz, Departamento de Pediatria, Faculdade de Medicina da Bahia, UFBA, Salvador, BA, Brasil. Professor adjunto, Departamento de Pediatria, Faculdade de Medicina da Bahia, UFBA, Salvador, BA, Brasil.

This article is part of Master's thesis entitled "Prevalência de sobrepeso e obesidade baseada em índices antropométricos entre crianças e adolescentes de escolas privadas de Salvador -Bahia"(Prevalence of overweight and obesity based on anthropometric indices, among children and adolescents at private schools in Salvador - Bahia), submitted on February 23, 2003 to the Graduate Program in Medicine and Health at the Medical School, Universidade Federal da Bahia (UFBA), Salvador, BA, Brazil.

Suggested citation: Boa-Sorte N, Neri LA, Leite ME, Brito SM, Meirelles AR, Luduvice FB, et al. Maternal perceptions and self-perception of the nutritional status of children and adolescents from private schools. J Pediatr (Rio J). 2007;83(4):349-356.

Manuscript received Dec 13 2006, accepted for publication May 302007.

doi 10.2223/JPED.1678 


\section{Introduction}

Childhood obesity, already endemic in developed countries, has been increasing rapidly in developing countries. ${ }^{1-3}$ In Brazil, while there are regional differences, the increase in the number of overweight children and adolescents is well-established. ${ }^{1,2,4}$ In the Northeast region, in 1989 , the prevalence of obese children under 5 years old was $2.5 \%$, becoming $4.5 \%$ by $1996 .^{2}$ Among adolescents, the prevalence of overweight and obesity reaches 12.1 and $10.8 \%$ in the Southeast and Northeast regions, respectively. ${ }^{1}$

Excessive weight is related to serious metabolic changes, such as hyperinsulinemia and peripheral insulin resistance, increased cardiovascular risk, orthopedic complications and psychosocial disorders, which affect quality of health as early as during childhood, resulting in an increase in diseases and morbidity factors among adolescents and adults. ${ }^{2-6}$ Furthermore, a high body mass index (BMI) during childhood and adolescence increases the chances of this obesity being continued into adulthood, and this risk increases according to the severity and duration of the obesity. ${ }^{5,7}$

Therefore, recognition by parents and/or healthcare providers of the problem in childhood is something that should be encouraged, since treatment of childhood obesity is very often neglected by families and doctors. ${ }^{5,8,9}$ On the other hand, parents tend to only consider overweight a problem when there is some type of compromise involved, particularly to physical activity, ${ }^{10}$ although they do associate obesity with increased risk of diseases and dysfunctions. ${ }^{11}$

Programs for early intervention in pediatric obesity depend on parents' participation and, in the first instance, on their capacity to correctly recognize the nutritional condition of their children. ${ }^{10,12}$ Furthermore, the construction of feeding habits and patterns of physical activity in children and adolescents, which is the primary target of childhood obesity treatment, suffers significant influence from the family environment and parents' attitudes. ${ }^{4,10}$

Correct perception by the family and the child or adolescent themselves in relation to overweight may be what is required for them to seek specialist professional help and to comply with the treatment proposed. For this reason, this study was carried out with the objective of describing and comparing maternal perceptions and those of the children/adolescents themselves of their nutritional status with relation to their classification by BMI, identifying factors associated with erroneous perceptions, among children and adolescents of higher socioeconomic status in Salvador, Bahia, Brazil.

\section{Methods}

This was a cross-sectional study with non-random sampling, carried out between June and November 2002 at four private primary and secondary schools in the city of Salvador, BA, Brazil, attended by middle class and upper middle class children. A research team (one pediatrician, three nutritionists and four nutrition students) assessed the nutritional status of 2,216 students aged from 6 to 19 years, employing BMI values as the diagnostic criterion. The values described by Must et al. ${ }^{13}$ were adopted, which are separated by sex and age, with cutoff points defined at the 5 th, 85 th and 95th percentiles delineating four groups: below the 5th percentile, underweight; between the 5 th percentile and the 85th percentile, well-nourished; between the 85th and 95th percentiles, risk of overweight; above the 95th percentile, overweight. $^{14}$

At each of the schools parents or guardians were given a free and informed consent form and their children were only included in the study once consent had been granted. All participants were weighed using a SECA 100 digital balance, accurate to $100 \mathrm{~g}$, with a $150 \mathrm{~kg}$ capacity and duly calibrated by a specialized company according to criteria defined by the National Institute of Metrology, Standardization and Industrial Quality (INMETRO - National Institute of Metrology, Standardization and Industrial Quality). Height was measured using a SECA 208 portable stadiometer, accurate to $0.1 \mathrm{~cm}$ and with a $200 \mathrm{~cm}$ capacity. Measurements were taken in triplicate, and the mean of the three was used to calculate BMI, using the formula weight $(\mathrm{kg}) /$ height $^{2}(\mathrm{~m})$.

Before the anthropometric measurements were taken, each student was requested to reply to a questionnaire, based on earlier studies, ${ }^{15,16}$ and containing the following questions: (1) What do you think about your weight? (2) What do you think about the amount of food you eat? (3) What do you think of the quality of your food? (4) Are you on a diet to try and lose weight? and (5) Do you do physical exercise? The questionnaire was completed in a separate room with one of the members of the research team available to clear up any doubts, although this person was not allowed to interfere with replies, as had been explained previously. Only the student who was completing the questionnaire was allowed to be in the room with the researcher so that their answers would not be influenced by other children. Possible replies were normal, too heavy or too light for the question on weight perception; too little, enough or too much for the question on the quantity of food eaten habitually; good, normal or poor with relation to the quality of food; and yes or no for the last two questions on dieting and physical exercise. The option "don't know" was also available for all questions and was ignored in analyses. Physical exercise was quantified in numbers of hours/week and described according to the type of activity (football, capoeira, swimming, etc.). 
The same questions, with the necessary adaptations and additions of questions relating to family history of diabetes, cardiovascular disease and obesity, were sent to the students' mothers.

The replies to the questionnaires were compared with nutritional status classified by BMI, assessing the perception of the students themselves and their mothers. Excessive weight was defined as BMI $\geq$ the 85 th percentile. Age was categorized into two groups: children ( 6 to 9 years) and adolescents (10 to 19 years). The unweighted kappa index and linear-weighted kappa were used to assess agreement between students and their mothers in relation to their perceptions of overweight. Chi-square was used to assess differences in proportions. Descriptive measurements were employed, followed by bivariate analysis of the students' self-perception and their mothers' perception (dependent variables), defined as correct or incorrect, and sex, age group, excessive weight, dieting and physical exercise (independent variables). Family history of obesity was also included in the analysis of maternal perceptions as an independent variable. The crude odds ratio (OR) was adjusted using backward stepwise logistic regression analysis, for all variables, with only those variables with $p<$ 0.05 remaining in the final model, since this was the figure chosen to define statistical significance. As a result of the influence of gender on the explanatory variables employed, a model of self-perception by sex was constructed. Analyses were performed using SPSS version 9.0 for Windows. The study was approved by the Research Ethics Committee at the Professor Edgar Santos University Hospital at the Universidade Federal da Bahia (UFBA).

\section{Results}

Of a total of 2,730 students enrolled at the four schools, $2,216(81.2 \%)$ students were authorized to undergo nutritional assessment and did so. Of this total, 370 (16.7\%) students did not complete the questionnaire and 105 (4.7\%) replied with the "don't know" option when asked about their own weight and were excluded. Therefore, 1,741 (78.6\%) questionnaires were considered valid. When those who replied to the questionnaire were compared with those who didn't, greater losses were observed among the boys (18 vs. $14.5 \% ; p=0.023)$, children ( 30.3 vs. $14.3 \% ; p<0.001)$ and overweight students (20.4 vs. $13.7 \% ; p=0.001$ ).

Distribution by sex demonstrated that there was a greater participation of females, making up $54 \%$ of the sample. Age varied from 6 to 19 years, with a mean of 13.15 years (standard deviation: 2.32 ) and median of 13 years. A total of 169 children (9.7\%) and 1,572 adolescents were studied, with 1,080 of these being in early adolescence (10 to 14 years), 466 in mid adolescence ( 15 to 17 years) and 26 in final adolescence (18 to 19 years).
The nutritional classification of students revealed that 70 (4.0\%) students were underweight, 1,374 (78.9\%) were well-nourished, 207 (11.9\%) were at risk of overweight and $90(5.2 \%)$ were overweight. Self perception was correct, irrespective of nutritional classification, in 1,128 students $(64.8 \%)$, while $292(16.8 \%)$ overestimated their own weight and 321 students $(18.4 \%)$ underestimated their own weight in relation to their classification according to BMI (Table 1).

Of 468 students who thought their weight was excessive, $271(57.9 \%)$ were overestimating their weight and $79.7 \%$ of these were female $(p<0.001)$. Erroneous self-perception among students diagnosed as overweight was predominantly present among the boys $(p<0.001)$. The same was true of students who underestimated their own weight $(p<0.001)$.

A total of 838 mothers returned their questionnaires ( $37.8 \%$ of the 2,216 sent out). The majority of students returned with authorization, but without the questionnaire filled out. Of those that did respond, 11 were discarded because they had unanswered questions or answered with "don't know", making a total of 827 valid questionnaires. Nutritional classification of these students demonstrated that 35 (4.2\%) were underweight, 640 (77.4\%) were well-nourished, 101 (12.2\%) were at risk of overweight and $51(6.2 \%)$ were overweight. Comparison of mothers who replied with those who didn't revealed greater losses among mothers of boys ( $67.4 \mathrm{vs} .57 .5 \% ; \mathrm{p}<0.001)$ and adolescents (66.6 vs. $28.0 \% ; p<0.001$ ), but did not detect differences in terms of the presence of overweight ( 64.8 vs. $62.2 \%$; $=$ $0.326)$. In relation to perceived nutritional status, 623 mothers $(75.3 \%)$ had the correct opinion of their child's weight, $52(6.3 \%)$ overestimated it and $152(18.4 \%)$ underestimated their child's true weight (Table 1 ).

The bivariate analysis (Table 2 ) detected that children and girls were most likely to have an incorrect self-perception. In the adjusted model, the association was maintained between incorrect self-perception and being between 6 and 9 years old (adjusted OR $=1.59 ; 95 \%$ CI 1.15-2.20). Female sex and physical exercise had opposite tendencies, increasing and reducing self-perception error, respectively.

In the analysis of factors associated with incorrect self-perception among the boys and girls, the opposite association was observed for each sex, with a positive association between being overweight and having an incorrect perception among males (OR $=1.96$; 95\%CI 1.37-2.81) and a negative association among females ( $O R=$ $0.30 ; 95 \%$ CI $0.18-0.50)$. The reverse was observed for dieting (Table 3).

With relation to mothers' perceptions of the students' weight (Table 4), the bivariate analysis indicated a positive association between incorrect maternal perception and children aged from 6 to 9 years $(\mathrm{OR}=2.23$; $95 \% \mathrm{CI}$ 
1.56-3.19) and between incorrect maternal perception and overweight ( $\mathrm{OR}=3.32 ; 95 \% \mathrm{CI} 2.29-4.82)$. When adjusted for the remaining variables in the model, the association was maintained for both variables, with the presence of overweight being the principal characteristic associated with incorrect perception after adjustments (adjusted $\mathrm{OR}=3.02$; $95 \%$ CI 2.05-4.46).

\section{Discussion}

The prevalence of overweight and obesity among children in Salvador has been described before and was observed to be more frequent among students from private schools and in association with higher incomes. ${ }^{17}$ This was the reason for choosing private schools students as the subjects of this study. Although the sample was obtained by convenience, which is a limitation to extrapolation of the results, the rates of risk of overweight (11.2\%) and overweight (5.4\%) are compatible with other studies undertaken in Brazil of samples with similar characteristics, ${ }^{1,17,18}$ which reinforces a tendency that has been identified on a worldwide level: the increase in overweight and obesity during childhood and adolescence. ${ }^{1,3,19,20}$
The use of questionnaires to measure the self-perception of weight of children and adolescents and of parents with respect to their children, has already been described in other studies, many of which used questions similar to those used here. ${ }^{10,16,21}$ Among the students, global agreement between self-perception and diagnosis based on BMI was $64.7 \%$, with the rate of correct perceptions being similar for underweight, well-nourished and overweight students. This finding was compatible with results found by another similar study carried out in Brazil. 22

Among the overweight students, $31.6 \%$ said they had normal weight/ the great majority of whom were male. There was also a significant proportion of boys among those who underestimated their weight. In the multivariate analysis of factors associated with incorrect perception, the presence of overweight had opposite influence for the two sexes, being a characteristic associated with incorrect perception among males and with correct perception among females.

The greatest underestimation and positive association found between being overweight and incorrect selfperception among the boys reinforces the stereotype that the

Table 1 - Comparison of agreement between mothers and their children in relation to weight perception with nutritional classification according to body mass index (Salvador, Brazil, 2002)

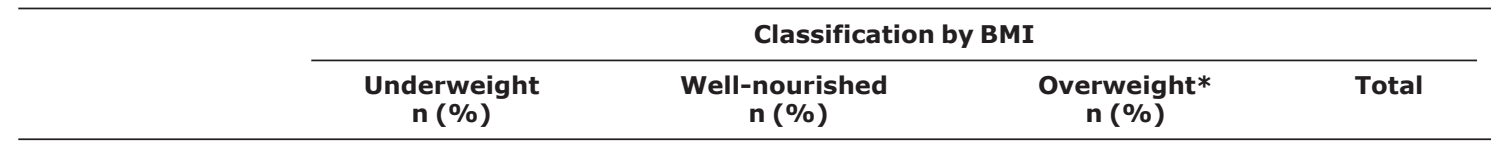

Self-perception of student's weight ${ }^{+}$

$\begin{array}{lcccc}\text { Too light } & 47(67.1) & 221(16.1) & 6(2.0) & 274 \\ \text { Normal } & 21(30.0) & 884(64.3) & 94(31.6) & 999 \\ \text { Too heavy } & 02(2.9) & 269(19.6) & 197(66.3) & 468 \\ \text { Total } & 70(100.0) & 1,374(100.0) & 297(100.0) & 1,741\end{array}$

Maternal perception of student's weight ${ }^{*}$

$\begin{array}{lcccr}\text { Too light } & 23(65.7) & 83(13.0) & 00(0.0) & 106 \\ \text { Normal } & 11(31.4) & 517(80.8) & 69(45.4) & 597 \\ \text { Too heavy } & 01(2.9) & 40(6.2) & 83(54.6) & 124 \\ \text { Total } & 35(100.0) & 640(100.0) & 152(100.0) & 827\end{array}$

BMI = body mass index

* Includes students classified as at risk of being overweight and as overweight.

${ }^{+}$Global agreement=64.7\%; kappa=0.289 (95\%CI 0.245-0.332); linear-weighted kappa=0.330 (95\%CI 0.292-0.369); p<0.001.

${ }^{*}$ Global agreement $=75.3 \%$; kappa $=0.396(95 \%$ CI $0.328-0.463)$; linear-weighted kappa $=0.434(95 \%$ CI $0.372-0.497) ; p<0.001$. 
model of the "ideal of body and of masculinity is a body inflated with muscles," which is a risk factor for anabolic steroid use. ${ }^{23}$ Among the girls, thinness is considered the ideal for social acceptance and success, gaining prominence in the media, 24-26 which also explains the association observed between dieting and incorrect body selfperception. Furthermore, several different studies have reported that it is girls who most often use diets with nutritional restrictions in order to achieve a "slender body $^{\prime \prime 24,27-29}$ and they are also more likely to feel fat or be unsatisfied with their bodies, even when not overweight. 26,29

This behavior associated with female sex, also demonstrated in other studies carried out bin Brazil, 24,29 helps to explain the tendency to an association between female sex and greater frequency of incorrect self-perception of weight ( $O R=1.22 ; 95 \% C I 1.00-1.49$ ) identified in our study, since a major percentage of well-nourished students though they were overweight and dieted, irrespective of whether or not they were overweight.

Despite the relationship between female sex and more frequent errors in self-perception of weight, the only variable that still exhibited a positive association with incorrect self-perception after adjustment for all of the variables was age from 6 to 9 years (adjusted OR $=1.59 ; 95 \% \mathrm{CI}$ $1.15-2.20)$. In a study carried out with children aged 8 to 11 years, Pinheiro \& Giugliani ${ }^{26}$ demonstrated that there is a robust association between feeling fat and the perceived expectation of parents with relation to the weight of the child. In our study, the mothers' opinions about their children were much more incorrect about children aged 6 to 9 years, which could be reflected in the children's self-perception of their nutritional status.

In the model broken down by sex, physical exercise was maintained as a marker associated with correct

Table 2 - Variables associated with incorrect self-perception of weight in 1,741 private school students (Salvador, Brazil, 2002)

\begin{tabular}{|c|c|c|c|c|}
\hline \multirow[b]{2}{*}{ Variables } & \multicolumn{2}{|c|}{ Bivariate analysis } & \multicolumn{2}{|c|}{ Logistic regression } \\
\hline & OR & $95 \% \mathrm{CI}$ & OR & $95 \% \mathrm{CI}$ \\
\hline \multicolumn{5}{|l|}{ Sex } \\
\hline Female & 1.25 & $1.02-1.52$ & 1.22 & $1.00-1.49$ \\
\hline Male & 1 & & & \\
\hline \multicolumn{5}{|l|}{ Age (years) } \\
\hline 6-9 (child) & 1.49 & $1.08-2.06$ & 1.59 & $1.15-2.20$ \\
\hline 10-19 (adolescent) & 1 & & & \\
\hline \multicolumn{5}{|c|}{ Overweight (BMI $\geq \mathrm{p} 85$ )* } \\
\hline Yes & 0.92 & $0.71-1.20$ & & \\
\hline No & 1 & & & \\
\hline \multicolumn{5}{|l|}{ Dieting?* } \\
\hline Yes & 0.98 & $0.72-1.34$ & & \\
\hline No & 1 & & & \\
\hline \multicolumn{5}{|l|}{ Physical exercise? } \\
\hline Yes & 0.84 & $0.68-1.03$ & 0.81 & $0.66-1.00$ \\
\hline No & 1 & & & \\
\hline
\end{tabular}

$95 \% \mathrm{CI}=95 \%$ confidence interval $; \mathrm{BMI}=$ body mass index $; \mathrm{OR}=$ odds ratio

* Variables excluded from the final model, backward stepwise procedure. 
self-perception among females. Despite the practice of physical exercise being more common among the boys, ${ }^{24,30} \mathrm{a}$ finding also observed in our study, among girls these practices are generally associated with concern about the body. ${ }^{23}$ Furthermore, dieting is more common among women as a response to incorrect perceptions of their nutritional status, ${ }^{23,27,28}$ which is an association that was also observed in this study.

When we analyzed the losses due to failure of students to complete the questionnaires, and based on the fact that there were greater losses among the male sex, children and students with overweight and, for boys, we found an association between those two factors and incorrect self-perception of weight, we could speculate that the greater rate of refusal to complete the questionnaire among children with these characteristics may be attributable to a negative self-image among overweight students. ${ }^{23}$ In contrast, the increased concern among women with weight and body image, particularly during adolescence, ${ }^{23,29}$ may explain their greater compliance.

Nevertheless, the strongest possibility of selection bias is due to the low numbers of questionnaires sent to students' homes that were returned. This large number of losses among the maternal replies may have had an influence on the magnitude of the association between incorrect maternal perception and age group from 6 to 9 years, since there was a significant predominance of absent replies among mothers of adolescents. The anthropometric data collection procedure adopted may have been the primary cause of losses, since return of the questionnaire was not made compulsory for anthropometric measurements to be taken, with only parental consent being required. Furthermore, the final results were provided to parents without demanding return of the questionnaires. Despite these limitations to fieldwork logistics, we cannot rule out the possibilities that students did not give their mothers the questionnaires or that the mothers had no interest in completing them.

Despite these sampling limitations, based on previous studies, which have demonstrated poorer weight perception among parents of children, ${ }^{15,16,21}$ and on the fact that there were no differences in terms of nutritional status between students whose mothers did or did not return the questionnaire, we believe that the association between overweight children and incorrect maternal perceptions, after adjustment for other independent variables included in the multivariate model (adjusted OR $=3.02: 95 \% \mathrm{CI}$ 2.05-4.46), corroborates the opinion that, in our study population, this fact was not the result of the losses, but reflects, in our milieu, a tendency that has already been identified in other locations.

The tendency to underestimate the weight of children with overweight or obesity was described in a study of 111

Table 3 - Variables associated with incorrect self-perception of weight in 1,741 private school students, by sex (Salvador, Brazil, 2002)

\begin{tabular}{lcc}
\hline Variables & OR (adjusted) & $\mathbf{9 5 \%} \mathbf{C I}$ \\
\hline Male sex & & \\
$\quad$ Children (6 to 9 years) & 1.62 & $1.00-2.61$ \\
Overweight (yes) & 1.96 & $1.37-2.81$ \\
Dieting (yes) & 0.35 & $0.19-0.67$ \\
Female sex & & \\
Physical activity (yes) & 0.69 & $0.52-0.92$ \\
Children (6 to 9 years) & 1.81 & $1.13-2.92$ \\
Overweight & 0.30 & $0.18-0.50$ \\
Dieting (yes) & 1.85 & $1.23-2.79$ \\
& & \\
\hline
\end{tabular}

$95 \% \mathrm{CI}=95 \%$ confidence interval; OR = odds ratio. 
Afro-American children aged 5 to 10 years, where $54 \%$ of mothers had an incorrect perception of their children's weights. ${ }^{21}$ A similar finding was described by Jackson et al. with the mothers of children aged 3 to 6 years. ${ }^{16}$ In this study, $55.3 \%$ of the mothers of overweight children did not recognize that their children had excess weight.

Among the possible causes that could be responsible for non-recognition of overweight among children's mothers, one can cite the belief that a "chubby" child is healthy and better cared for by its parents. Furthermore, many mothers believe that, as their children grow, the weight will be better distributed and the child will not become an obese adolescent. ${ }^{15}$

Recognition of overweight by parents is an important step towards the process of prevention, diagnosis and treatment of childhood obesity. ${ }^{5,9}$ Since many parents, especially those with less education, may not recognize the presence of overweight in their children, ${ }^{10,25}$ or even associate the condition with better health, seeking the help of a healthcare professional may occur late or the parents may not adequately take part in the treatment prescribed when overweight is diagnosed. ${ }^{15}$

Based on these facts and on the findings of this study, better publicity of the health risks for pediatric patients, primarily for children with overweight, is needed to raise parents' awareness of the condition to enable them to recognize it. Intervention policies aimed at adults, while both relevant and necessary, will not alone be enough to result in control of obesity.

Table 4 - Variables associated with incorrect perception of their child's weight by the 827 mothers who responded (Salvador, Brazil, 2002)

\begin{tabular}{|c|c|c|c|c|}
\hline \multirow[b]{2}{*}{ Variables } & \multicolumn{2}{|c|}{ Bivariate analysis } & \multicolumn{2}{|c|}{ Logistic regression } \\
\hline & OR & $95 \% \mathrm{CI}$ & OR & $95 \% \mathrm{CI}$ \\
\hline \multicolumn{5}{|l|}{ Sex* } \\
\hline Female & 0.79 & $0.58-1.09$ & & \\
\hline Male & 1 & & & \\
\hline \multicolumn{5}{|l|}{ Age (years) } \\
\hline 6-9 (child) & 2.23 & $1.56-3.19$ & 1.88 & $1.28-2.76$ \\
\hline 10-19 (adolescent) & 1 & & & \\
\hline \multicolumn{5}{|c|}{ Overweight (BMI $\geq$ p85) } \\
\hline Yes & 3.32 & $2.29-4.82$ & 3.02 & $2.05-4.46$ \\
\hline No & 1 & & & \\
\hline \multicolumn{5}{|l|}{ Dieting?* } \\
\hline Yes & 0.97 & $0.58-1.63$ & & \\
\hline No & 1 & & & \\
\hline \multicolumn{5}{|l|}{ Physical exercise?* } \\
\hline Yes & 1.11 & $0.78-1.57$ & & \\
\hline No & 1 & & & \\
\hline \multicolumn{5}{|c|}{ Family history of obesity* } \\
\hline Yes & 1.24 & $0.88-1.76$ & & \\
\hline No & 1 & & & \\
\hline
\end{tabular}

$95 \% \mathrm{CI}=95 \%$ confidence interval; $\mathrm{BMI}=$ body mass index; OR = odds ratio.

* Variables excluded from the final model, backward stepwise procedure. 


\section{References}

1. Abrantes MM, Lamounier JA, Colosimo EA. Prevalência de sobrepeso e obesidade em crianças e adolescentes das regiões Sudeste e Nordeste. J Pediatr (Rio J). 2002;78:335-40.

2. Escrivão MA, Oliveira FL, Taddei JA, Lopez FA. Obesidade exógena na infância e na adolescência. J Pediatr (Rio J). 2000;76 Supl 3:S305-10.

3. Hoffman DJ. Obesity in developing countries: causes and implications. Food, Nutrition and Agriculture. 2001;28:35-44.

4. Mello ED, Luft VC, Meyer F. Obesidade infantil: como podemos ser eficazes? J Pediatr (Rio J). 2004;80:173-82.

5. Schonfeld-Warden N, Warden CH. Pediatric obesity. An overview of etiology and treatment. Pediatr Clin North Am. 1997;44:339-61.

6. Ramin A, Rising R, Cedillo M, Lifshitz F. Obesity in Children. In: Lifshitz F, editor. Pediatric endocrinology. 4th ed. New York: Marcel Dekker; 2003. p. 823-58.

7. Guo SS, Wu W, Chumlea WC, Roche AF. Predicting overweight and obesity in adulthood from body mass index values in childhood and adolescence. Am J Clin Nutr. 2002;76:653-8.

8. Barlow SE, Trowbridge FL, Klish WJ, Dietz WH. Treatment of child and adolescent obesity: reports from pediatricians, pediatric nurse practitioners, and registered dietitians. Pediatrics. 2002;110(1 Pt 2):229-35.

9. Boog MC. Dificuldades encontradas por médicos e enfermeiros na abordagem de problemas alimentares. Rev Nutr. $1999 ; 12: 261-72$.

10. Etelson D, Brand DA, Patrick PA, Shirali A. Childhood obesity: do parents recognize this health risk? Obes Res. 2003;11:1362-8.

11. Davison KK, Birch LL. Weight status, parent reaction, and selfconcept in five-year-old girls. Pediatrics. 2001;107:46-53.

12. Golan M, Weizman A, Apter A, Fainaru M. Parents as the exclusive agents of change in the treatment of childhood obesity. Am J Clin Nutr. 1998;67:1130-5.

13. Must A, Dallal GE, Dietz WH. Reference data for obesity: 85th and 95th percentiles of body mass index (wt/ht2) and triceps skinfold thickness. Am J Clin Nutr. 1991;53:839-46.

14. US Preventive Services Task Force. Screening and interventions for overweight in children and adolescents: recommendation statement. Pediatrics. 2005;116:205-9.

15. Baughcum AE, Chamberlin LA, Deeks CM, Powers SW, Whitaker RC. Maternal perceptions of overweight preschool children. Pediatrics. 2000:106;1380-6.

16. Jackson J, Strauss CC, Lee AA, Hunter K. Parents' accuracy in estimating child weight status. Addict Behav. 1990;15:65-8.

17. Leão LSC, Araújo LMB, Moraes LTL, Assis AM. Prevalência de obesidade em escolares de Salvador, Bahia. Arq Bras Endocrinol Metab. 2003;47:151-7.
18. Balaban G, Silva GA. Prevalência de sobrepeso e obesidade em crianças e adolescentes de uma escola da rede privada de Recife. J Pediatr (Rio J). 2001;77:96-100.

19. Ogden CL, Flegal KM, Carroll MD, Johnson CL. Prevalence and trends in overweight among US Children and Adolescents, 1999-2000. JAMA. 2002;288:1728-32.

20. Livingstone B. Epidemiology of childhood obesity in Europe. Eur J Pediatr. 2000;159 Suppl 1: S14-34.

21. Young-Hyman D, Herman LJ, Scott DL, Schlundt DG. Care giver perception of children's obesity-related health risk: a study of African American families. Obes Res. 2000;8:241-8.

22. Branco LM, Hilário MOE, Cintra IP. Percepção e satisfação corporal em adolescentes e a relação com seu estado nutricional. Rev Psiquiatr Clin. 2006;33:292-6.

23. Iriart JAB, Andrade TM. Musculação, uso de esteróides anabolizantes e percepção de risco entre jovens fisiculturistas de um bairro popular de Salvador, Bahia, Brasil. Cad Saude Publica. 2002;18:1379-87.

24. Braggion GF, Matsudo SMM, Matsudo VKR. Consumo alimentar, atividade física e percepção da aparência corporal em adolescentes. Rev Bras Ciên Mov Brasilia. 2000;8:15-21.

25. Padgett J, Biro FM. Different shapes in different cultures: body dissatisfaction, overweight, and obesity in African-American and Caucasian females. J Pediatr Adolesc Gynecol. 2003; 16:349-54.

26. Pinheiro AP, Giugliani ER. Who are the children with adequate weight who feel fat? J Pediatr (Rio J). 2006;82:232-5.

27. McVey G, Tweed S, Blackmore E. Dieting among preadolescent and young adolescent females. CMAJ. 2004;170:1559-61.

28. Wong Y, Chen SL, Chan YC, Wang MF, Yamamoto S. Weight satisfaction and dieting practices among college males in Taiwan. J Am Coll Nutr. 1999;18:223-8.

29. Nunes MA, Olinto MTA, Barros FC, Camey S. Influ\&\#xea; ncia da percep\&\#xe7; ão do peso e do \&\#xed;ndice de massa corporal nos comportamentos alimentares anormais. Rev Bras Psiquiatr. $2001 ; 23: 21-7$.

30. Costa MCO, Silva MCM, Santos JS, Teles C, Souza KEP, Melo BO. Estilo de vida de adolescentes: consumo alimentar, de bebida alcoólica e atividade física em Teixeira de Freitas-Bahia. Rev Baiana Saúde Pública. 2004;28:151-66.

Correspondence:

Ney Boa-Sorte

Rua Almirante Barroso, 96/301, Edifício Mirante da Paciência,

Rio Vermelho

CEP 41950-350 - Salvador, BA - Brazil

Tel.: +55 (71) 3334.1105

E-mail: neyboasorte@uol.com.br 